\title{
Performance of Gradient-Corrected and Hybrid Density Functional Theory: Role of the Underlying Local Density Approximation and the Gradient Correction
}

\author{
Bun Chan, ${ }^{* \dagger}$ Peter M. W. Gill, ${ }^{* \dagger}$ and Leo Radom $*{ }^{\dagger}$ \\ ${ }^{\dagger}$ School of Chemistry and ARC Centre of Excellence for Free Radical Chemistry and Biotechnology, University of Sydney, Sydney, \\ NSW 2006, Australia \\ ${ }^{\ddagger}$ Research School of Chemistry, Australian National University, Canberra, ACT 0200, Australia
}

\section{Supporting Information}

\begin{abstract}
We have analyzed the performance of several widely used density functional theory procedures, namely B-P86, BPW91, B-LYP, B3-P86, B3-PW91, and B3-LYP, for the E3 set of thermochemical properties. Each of these procedures employs a local density approximation (LDA) functional and a gradient correction for the correlation energy. We find that the VWN3 LDA functional in B-P86, B-PW91, B3-P86, and B3-PW91 leads to extremely large deviations from benchmark values for heats of formation (as large as $-455.6 \mathrm{~kJ} \mathrm{~mol}^{-1}$ for the B-PW91(VWN3) value for azulene!) and that VWN3 also gives significant errors in the calculated ionization energies and electron affinities. The PW91 gradient correction generally performs much better than P86 for heats of formation, and we propose that this is because P86 severely violates a uniform scaling condition that PW91 almost satisfies. Thus, of the procedures that we have examined, we recommend the use of the VWN5 or PW92 forms of LDA, preferably in combination with the PW91 gradient correction. Our results confirm previous findings that VWN3 is a more suitable LDA than VWN5 for B3-LYP, and we attribute this to fortuitous error cancellation between understabilization of molecules by LYP and overstabilization by VWN3.
\end{abstract}

\section{INTRODUCTION}

Since the inception of Kohn-Sham density functional theory (DFT), advances in DFT procedures have played a critical role in driving computational quantum chemistry to become an indispensable tool for chemists. ${ }^{1}$ Contemporary DFT procedures are typically based on the local density approximation (LDA) to the uniform electron gas (UEG). The exact LDA exchange functional is the widely used Slater (S) functional, ${ }^{2}$ but the exact LDA correlation functional is not known and a number of approximations, for example, VWN $3,{ }^{3} \mathrm{VWN} 5{ }^{3}$ $\mathrm{PZ81}^{4}{ }^{4}$ and PW92, ${ }^{5}$ are commonly employed. The LDA also serves as a platform on which various refinements are built. One of the most significant of these is the generalized gradient approximation (GGA), in which information on the density gradient is taken into account. Numerous further refinements to the GGA model have been introduced, notably hybridGGAs, which include a fraction of Fock exchange.

Among the many widely used GGA procedures is B-P86, which combines the B88 exchange functional ${ }^{6}$ and the P86 correlation functional, ${ }^{7}$ using PZ81 as the underlying LDA correlation functional. The corresponding three-parameter hybrid-GGA, B3-P86, is also popular and, in the implementation of B3-P86 in the Gaussian program, ${ }^{8}$ the VWN3 functional is employed as the underlying LDA correlation functional. Despite the proven performance of B-P86 and B3-P86 for many applications, it is known that, for some thermochemical properties such as heats of formation $\left(\Delta H_{\mathrm{f}} \mathrm{s}\right)$, ionization energies (IEs), and electron affinities (EAs), these functionals are often less accurate ${ }^{9,10}$ than analogous procedures that employ the PW91 ${ }^{11}$ or LYP ${ }^{12}$ correlation functionals, i.e., BPW91 and B3-PW91, ${ }^{13}$ and B-LYP ${ }^{14}$ and B3-LYP. ${ }^{15}$

The uneven performance of B-P86 and B3-P86 across thermochemical properties is of both fundamental interest and practical importance because of their popularity with computational chemists. Motivated by this, we aim in the present investigation to shed light on the factors that contribute to the varying performance of these two procedures. We provide guidelines in selecting procedures to try to help avoid pitfalls that may otherwise lead to exceedingly large errors.

\section{COMPUTATIONAL DETAILS}

Standard DFT calculations ${ }^{1}$ were carried out with Gaussian $09^{8}$ and Orca 2.8. ${ }^{16}$ All geometries were optimized using $\mathrm{BMK}^{17}$ with the $6-31+\mathrm{G}(2 \mathrm{df}, \mathrm{p})$ basis set. This level of theory has previously been shown to provide a cost-effective means of obtaining reliable geometries. ${ }^{18}$ Energies at $0 \mathrm{~K}$ incorporate zero-point vibrational energies, obtained with scaled (0.9770) BMK/6-31+G(2df,p) harmonic frequencies, while $298 \mathrm{~K}$ enthalpies additionally include thermal corrections derived from frequencies scaled by $0.9627 .^{18,19}$ Unless otherwise noted, single-point energies were obtained with the 6-311++G(3df,3pd) basis set. For Pd and Ru, the def2-TZVP basis set was employed, together with the matching effective core potential. ${ }^{20}$ We have examined the B-P86, B-LYP, and B-PW91 procedures, as well as their three-parameter hybrid variants $\mathrm{B} 3$ -

Special Issue: Berny Schlegel Festschrift

Received: July 16, 2012

Published: September 25, 2012 
P86, B3-LYP, and B3-PW91, ${ }^{21}$ exploring the performance of a number of LDA correlation functionals, namely VWN3, VWN5, PZ81, and PW92, within these procedures. We have employed the E3 $\operatorname{set}^{22}$ of accurate experimental and theoretical data ${ }^{23-34}$ as the benchmarks for testing the performance of the DFT procedures. All relative energies are reported in kilojoules per mole, and total energies are in hartree. The full details of the E3 set have been specified elsewhere, ${ }^{18,22}$ but we provide a summary of the test set in Table 1 .

Table 1. Summary of the E3 Set and Its Subsets Employed in the Present Study

\begin{tabular}{|c|c|c|}
\hline test set & property & ref \\
\hline E3 & $\mathrm{E} 2+\mathrm{DSD}^{\prime}$ & 22 \\
\hline $\mathrm{E} 2$ & $\mathrm{E} 0+\mathrm{G} 2 / 97^{\prime}+\mathrm{E} 1$ & 18 \\
\hline E0 & W4/08 + DBH24 + HB16 + WI9/04 & 18 \\
\hline W4/08 & atomization energies & 23 \\
\hline $\mathrm{DBH} 24$ & reaction barriers & 24 \\
\hline HB16 & hydrogen bonds & 25 \\
\hline WI9/04 & weak interactions & 26 \\
\hline $\mathrm{G} 2 / 97^{\prime}$ & $\mathrm{G} 2 / 97^{\prime} \Delta H_{\mathrm{f}}+\mathrm{IE}+\mathrm{EA}+\mathrm{PA}$ & 18 \\
\hline $\mathrm{G} 2 / 97^{\prime} \Delta H_{\mathrm{f}}$ & heats of formation & 18,27 \\
\hline IE & ionization energies & 27 \\
\hline EA & electron affinities & 27 \\
\hline PA & proton affinities & 27 \\
\hline E1 & $\mathrm{G} 3 / 99^{\prime} \Delta H_{\mathrm{f}}+\mathrm{ADD}+\mathrm{ABS}+\mathrm{PR} 8$ & 18 \\
\hline $\mathrm{G} 3 / 99^{\prime} \Delta H_{\mathrm{f}}$ & heats of formation & 18,28 \\
\hline $\mathrm{ADD}$ & radical addition energies & 29 \\
\hline ABS & radical abstraction energies & 29 \\
\hline PR8 & pericyclic reaction barriers & 18,30 \\
\hline $\mathrm{DSD}^{\prime}$ & $\mathrm{S} 22+\mathrm{MB} 08+\mathrm{Pd}+$ Grubbs & 22 \\
\hline S22 & weak interactions & 31 \\
\hline MB08 & artificial molecules & 32 \\
\hline $\mathrm{Pd}$ & Pd-catalyzed reaction profiles & 33 \\
\hline Grubbs & Grubbs reaction profile & 34 \\
\hline
\end{tabular}

\section{RESULTS AND DISCUSSION}

Performance of Pure-GGA Functionals B-P86, BPW91, and B-LYP. For the pure-GGA procedures, we have focused mainly on B-P86 and B-PW91, since the gradient corrections in the P86 and PW91 functionals can be paired with a variety of correlation LDAs. The mean absolute deviations (MADs) from benchmark values for the various pure-GGA procedures for the E3 set and its subsets are shown in Table 2, while the corresponding mean deviations (MDs) are listed in Table 3. We first note that B-PW91(VWN5), B-PW91(PW92), and B-LYP are the best performing methods, with MADs of $\sim 30 \mathrm{~kJ} \mathrm{~mol}^{-1}$ for the complete E3 set. However, the dependence of the MAD results on the underlying LDA correlation functional is striking. For example, the B-PW91(VWN5) value $\left(29.2 \mathrm{~kJ} \mathrm{~mol}^{-1}\right)$ is less than half of the BPW91(VWN3) value $\left(66.4 \mathrm{~kJ} \mathrm{~mol}^{-1}\right)$, and similarly, the BP86(VWN5) value $\left(45.5 \mathrm{~kJ} \mathrm{~mol}^{-1}\right)$ is much smaller than the BP86(VWN3) value $\left(66.0 \mathrm{~kJ} \mathrm{~mol}^{-1}\right)$.

Inspection of the results for the various subsets of E3 shows that, while most of the DFT procedures examined in the present study yield similar MADs for most thermochemical properties, there are very large variations in their performance for atomization energies (W4/08) and heats of formation (G2/ $97^{\prime} \Delta H_{\mathrm{f}}$ and G3/99' $\Delta H_{\mathrm{f}}$ ). For the G3/99' $\Delta H_{\mathrm{f}} \mathrm{s}$, for which the range of $\mathrm{MADs}$ is the largest among all the subsets, B-
PW91(PW92) gives the smallest MAD (44.9 kJ mol-1), while B-PW91(VWN3) yields the largest MAD of $219.5 \mathrm{~kJ} \mathrm{~mol}^{-1}$ and the largest deviation for an individual molecule of $-455.6 \mathrm{~kJ}$ $\mathrm{mol}^{-1}$ (for the $\Delta H_{\mathrm{f}}$ of azulene)! In addition, for IEs and EAs, while most procedures give similar performance (MADs $\sim 20-$ $30 \mathrm{~kJ} \mathrm{~mol}^{-1}$ for IEs and $10-20 \mathrm{~kJ} \mathrm{~mol}^{-1}$ for EAs), BP86(VWN3) and B-PW91(VWN3) yield much larger MADs $\left(\sim 40-60 \mathrm{~kJ} \mathrm{~mol}^{-1}\right)$. We note that our findings for BP86(PZ81) and B-PW91(PW92) for the G2/97' $\Delta H_{\mathrm{f}}$, G2/ $97^{\prime} \mathrm{IE}, \mathrm{G} 2 / 97^{\prime} \mathrm{EA}$, and G3/99' $\Delta H_{\mathrm{f}}$ sets are consistent with those of Staroverov, Scuseria, Tao, and Perdew. ${ }^{9 \mathrm{~b}}$

We can see that for B-P86, the MADs for W4/08, G2/97' $\Delta H_{\mathrm{f}}, \mathrm{G} 3 / 99^{\prime} \Delta H_{\mathrm{f}}, \mathrm{G} 2 / 97^{\prime} \mathrm{IE}$, and G2/97' EA decrease with the underlying LDA in the order: VWN3 > PZ81 > VWN5 PW92. We observe a similar dependence of the performance of B-PW91 on the LDA, with the MADs for these five sets decreasing in the order: VWN3 > VWN5 PW92. In fact, when VWN3 is employed in either B-P86 or B-PW91, extremely large deviations from experiment are observed for $\Delta H_{\mathrm{f}}$. For instance, the MADs for the G3/99' $\Delta H_{\mathrm{f}}$ set are greater than $200 \mathrm{~kJ} \mathrm{~mol}^{-1}$ in both cases. An inspection of the $\mathrm{MD}$ values in Table 3 indicates that there is a systematic underestimation of $\Delta H_{\mathrm{f}}$ values or, equivalently, overestimation of atomization energies. We conclude that these functionals overstabilize molecules relative to their constituent atoms.

On the Nature of the LDA Functionals and Gradient Corrections. The four different LDA approximations, namely VWN3, PZ81, VWN5, and PW92, differ from one another primarily in the way that the Ceperley-Alder data ${ }^{35}$ for the UEG are interpolated (for intermediate densities) and extrapolated (for densities outside the Ceperley-Alder range). For these interpolations and extrapolations, PZ81 utilizes the von Barth-Hedin scheme ${ }^{36}$ and VWN3 employs the "form III" expression of Vosko, Wilk, and Nusair, ${ }^{3}$ while VWN5 and PW92 use the "form V" expression. ${ }^{3}$ In addition, PZ81 includes self-interaction correction terms. In general, the accuracy with which these four functionals model the energy of the UEG improves in the order: VWN3 < PZ81 < VWN5 PW92. The observed trends in accuracy associated with the various underlying LDA functionals for B-P86 and B-PW91 are thus consistent with their intrinsic accuracies.

Although B-P86(PZ81), B-P86(VWN5), and B-P86(PW92) give reasonable MADs for IEs $\left(\sim 23 \mathrm{~kJ} \mathrm{~mol}^{-1}\right)$ and $\mathrm{EAs}(\sim 17 \mathrm{~kJ}$ $\left.\mathrm{mol}^{-1}\right)$, very large MADs of more than $120 \mathrm{~kJ} \mathrm{~mol}^{-1}$ are still observed for $\Delta H_{\mathrm{f}}$ (Table 2). In contrast, B-PW91(VWN5) and B-PW91(PW92) perform much better, with $\Delta H_{\mathrm{f}}$ MADs around $30-50 \mathrm{~kJ} \mathrm{~mol}^{-1}$. What feature of B-P86 is responsible for this unexpectedly large difference?

In most cases, if an atom or molecule is compressed through a uniform scaling of its coordinates, its correlation energy becomes more negative. However, Levy ${ }^{37}$ has shown that, in nondegenerate cases, it flattens out and approaches a limiting value in the high-density regime. A respectable correlation functional should therefore yield correlation energies that are bounded from below under such a scaling. ${ }^{37}$ However, whereas PW91 is almost satisfactory in this regard, P86 fails to respect this requirement, ${ }^{38,39}$ and we propose that the poor performance of the B-P86 procedure can be traced primarily to its inflated correlation energies for high densities. When a molecule is formed from atoms, its electron density is generally more compact than it was in the free atoms, ${ }^{40,41}$ and P86 therefore tends to overstabilize molecules relative to their component atoms. In contrast, because PW91 almost satisfies 
Table 2. Mean Absolute Deviations from Benchmark Values $\left(\mathrm{kJ} \mathrm{mol}^{-1}\right)$ for the B-P86, B-PW91, and B-LYP Procedures with a Variety of Underlying Correlation LDA Functionals for the E3 Set and its Subsets ${ }^{a}$

\begin{tabular}{|c|c|c|c|c|c|c|c|c|}
\hline \multirow{2}{*}{$\frac{\text { procedure }}{\text { LDA functional }}$} & \multicolumn{4}{|c|}{ B-P86 } & \multicolumn{3}{|c|}{ B-PW91 } & \multirow[t]{2}{*}{ B-LYP } \\
\hline & VWN3 & PZ81 & VWN5 & PW92 & VWN3 & VWN5 & PW92 & \\
\hline E3 & 66.0 & 51.9 & 45.5 & 45.4 & 66.4 & 29.2 & 29.2 & 31.8 \\
\hline $\mathrm{E} 2$ & 80.6 & 60.2 & 50.8 & 50.7 & 80.8 & 27.3 & 27.3 & 29.1 \\
\hline E0 & 51.4 & 46.3 & 39.1 & 39.3 & 53.8 & 29.8 & 30.0 & 25.7 \\
\hline W4/08 & 67.4 & 59.9 & 49.1 & 49.4 & 71.4 & 36.7 & 37.0 & 30.1 \\
\hline $\mathrm{DBH} 24$ & 34.9 & 34.9 & 35.3 & 35.0 & 33.1 & 28.9 & 28.9 & 31.9 \\
\hline HB16 & 4.6 & 4.1 & 4.1 & 4.0 & 5.4 & 3.7 & 3.7 & 2.3 \\
\hline WI9/04 & 2.1 & 2.2 & 2.2 & 2.2 & 1.8 & 2.7 & 2.7 & 2.4 \\
\hline $\mathrm{G} 2 / 97^{\prime}$ & 76.3 & 49.5 & 43.3 & 43.1 & 71.6 & 23.9 & 23.8 & 24.5 \\
\hline $\mathrm{G} 2 / 97^{\prime} \Delta H_{\mathrm{f}}$ & 119.3 & 97.6 & 81.3 & 80.8 & 121.2 & 32.1 & 32.1 & 29.9 \\
\hline IE & 47.6 & 22.3 & 23.2 & 23.1 & 40.2 & 25.1 & 24.9 & 29.5 \\
\hline EA & 59.9 & 18.7 & 17.5 & 17.5 & 47.9 & 11.3 & 11.2 & 10.9 \\
\hline PA & 5.4 & 5.7 & 5.6 & 5.6 & 6.2 & 5.9 & 5.9 & 6.0 \\
\hline E1 & 122.1 & 96.5 & 78.5 & 78.0 & 129.2 & 30.8 & 31.0 & 41.6 \\
\hline $\mathrm{G} 3 / 99^{\prime} \Delta H_{\mathrm{f}}$ & 208.2 & 162.4 & 130.6 & 129.6 & 219.5 & 44.9 & 45.2 & 59.6 \\
\hline $\mathrm{ADD}$ & 5.3 & 6.2 & 6.3 & 6.5 & 8.1 & 9.9 & 9.9 & 26.5 \\
\hline ABS & 14.2 & 14.1 & 13.4 & 13.5 & 14.5 & 13.5 & 13.6 & 13.8 \\
\hline PR8 & 21.6 & 20.7 & 20.5 & 20.4 & 25.1 & 17.9 & 17.9 & 13.7 \\
\hline $\mathrm{DSD}^{\prime}$ & 30.2 & 31.7 & 32.3 & 32.4 & 31.0 & 33.9 & 33.9 & 38.4 \\
\hline $\mathrm{S} 22$ & 14.7 & 15.7 & 15.8 & 15.8 & 12.5 & 20.0 & 19.9 & 18.8 \\
\hline MB08 & 33.8 & 35.4 & 36.2 & 36.3 & 35.6 & 37.8 & 37.8 & 43.1 \\
\hline $\mathrm{Pd}$ & 21.1 & 21.7 & 21.3 & 21.4 & 21.3 & 18.0 & 18.1 & 15.9 \\
\hline Grubbs & 24.4 & 28.1 & 28.3 & 28.5 & 14.3 & 35.7 & 35.7 & 61.0 \\
\hline
\end{tabular}

${ }^{a_{T}}$ The 6-311++G(3df,3pd) basis set was employed for all elements except Pd and Ru, for which the def2-TZVP basis set was used, together with the matching effective core potential.

Table 3. Mean Deviations from Benchmark Values $\left(\mathrm{kJ} \mathrm{mol}^{-1}\right)$ for the B-P86, B-PW91, and B-LYP Procedures with a Variety of Underlying Correlation LDA Functionals for the E3 Set and its Subsets ${ }^{a}$

\begin{tabular}{|c|c|c|c|c|c|c|c|c|}
\hline \multirow{2}{*}{$\begin{array}{c}\text { procedure } \\
\text { LDA functional }\end{array}$} & \multicolumn{4}{|c|}{ B-P86 } & \multicolumn{3}{|c|}{ B-PW91 } & \multirow[t]{2}{*}{ B-LYP } \\
\hline & VWN3 & PZ81 & VWN5 & PW92 & VWN3 & VWN5 & PW92 & \\
\hline E3 & -16.3 & -19.7 & -16.3 & -16.3 & -17.5 & -3.3 & -3.0 & 2.8 \\
\hline E2 & -24.9 & -28.4 & -23.6 & -23.3 & -29.0 & -3.8 & -3.4 & 10.0 \\
\hline E0 & 39.3 & 33.6 & 25.7 & 26.0 & 41.9 & 13.1 & 13.1 & 9.0 \\
\hline W4/08 & 66.9 & 58.4 & 46.7 & 47.1 & 70.0 & 26.9 & 26.9 & 21.2 \\
\hline DBH24 & -34.9 & -34.9 & -35.3 & -35.0 & -33.1 & -28.9 & -28.9 & -31.9 \\
\hline HB16 & 3.5 & 2.5 & 2.5 & 2.4 & 4.8 & -0.4 & -0.4 & 0.7 \\
\hline WI9/04 & -2.1 & -2.2 & -2.2 & -2.2 & -1.8 & -2.7 & -2.7 & -2.4 \\
\hline G2/97' & -16.0 & -33.7 & -28.1 & -28.0 & -22.3 & -11.6 & -11.3 & -3.8 \\
\hline $\mathrm{G} 2 / 97^{\prime} \Delta H_{\mathrm{f}}$ & -118.7 & -96.2 & -79.2 & -78.7 & -120.4 & -20.8 & -19.9 & 10.0 \\
\hline IE & 42.3 & -3.8 & -5.0 & -5.2 & 33.8 & -13.3 & -13.5 & -21.7 \\
\hline EA & 59.9 & 17.6 & 15.9 & 15.9 & 47.9 & 3.7 & 3.8 & 1.1 \\
\hline $\mathrm{PA}$ & 0.8 & -1.6 & -1.3 & -1.4 & 4.1 & 4.0 & 3.9 & -5.9 \\
\hline E1 & -115.0 & -88.7 & -70.9 & -70.3 & -122.6 & -8.1 & -7.1 & 37.7 \\
\hline $\mathrm{G} 3 / 99^{\prime} \Delta H_{\mathrm{f}}$ & -208.2 & -162.4 & -130.6 & -129.6 & -219.5 & -20.5 & -18.7 & 55.0 \\
\hline $\mathrm{ADD}$ & 1.0 & 4.6 & 5.0 & 5.2 & -5.7 & 9.7 & 9.8 & 26.5 \\
\hline ABS & 14.2 & 14.1 & 13.4 & 13.5 & 14.5 & 13.5 & 13.6 & 13.8 \\
\hline PR8 & -21.6 & -20.7 & -20.5 & -20.4 & -25.1 & -17.9 & -17.9 & -5.9 \\
\hline $\mathrm{DSD}^{\prime}$ & 4.7 & 1.6 & 1.3 & 0.9 & 10.8 & -2.0 & -1.9 & -14.9 \\
\hline S22 & 14.7 & 15.7 & 15.8 & 15.8 & 12.5 & 20.0 & 19.9 & 18.8 \\
\hline MB08 & 4.1 & -0.2 & -0.6 & -1.1 & 12.7 & -5.6 & -5.5 & -23.6 \\
\hline $\mathrm{Pd}$ & -8.2 & -8.7 & -8.5 & -8.6 & -7.9 & -9.6 & -9.6 & -7.1 \\
\hline Grubbs & 24.4 & 28.1 & 28.3 & 28.5 & 14.3 & 35.7 & 35.7 & 61.0 \\
\hline
\end{tabular}

${ }^{a_{T}}$ The 6-311++G(3df,3pd) basis set was employed for all elements except Pd and Ru, for which the def2-TZVP basis set was used, together with the matching effective core potential.

the Levy scaling theorem, B-PW91 largely avoids this problem. Levy has made an analogous argument to explain the tendency of the pure LDA to overbind. ${ }^{37 b}$
Energy Convergence Behavior with Respect to Increasing Density. To explore further the energy convergence behavior with respect to electron density, we have 
calculated the correlation energies ${ }^{42}$ for the helium-like ions $\mathrm{H}^{-}, \mathrm{He}, \mathrm{Li}^{+}, \ldots, \mathrm{Ne}^{8+}$ using P86(VWN3), P86(VWN5), and PW91(VWN5), and these are compared with full CI energies in Table 4. We find that, whereas the full CI energies approach

Table 4. Correlation Energies (hartree) ${ }^{a}$ for Isoelectronic Two-Electron Ions $\mathrm{H}^{-}, \mathrm{He}, \mathrm{Li}^{+}, \ldots, \mathrm{Ne}^{8+}$

\begin{tabular}{|c|c|c|c|c|}
\hline method & P86 & P86 & PW91 & full CI \\
\hline LDA functional & VWN3 & VWN5 & VWN5 & - \\
\hline $\mathrm{H}^{-}$ & -0.07684 & -0.04343 & -0.03862 & -0.03292 \\
\hline $\mathrm{He}$ & -0.08120 & -0.04375 & -0.04553 & -0.04090 \\
\hline $\mathrm{Li}^{+}$ & -0.08558 & -0.04610 & -0.05066 & -0.04195 \\
\hline $\mathrm{Be}^{2+}$ & -0.09062 & -0.04996 & -0.05400 & -0.04290 \\
\hline $\mathrm{B}^{3+}$ & -0.09586 & -0.05439 & -0.05600 & -0.04328 \\
\hline $\mathrm{C}^{4+}$ & -0.10187 & -0.05980 & -0.05773 & -0.04349 \\
\hline $\mathrm{N}^{5+}$ & -0.10822 & -0.06569 & -0.05914 & -0.04363 \\
\hline $\mathrm{O}^{6+}$ & -0.11476 & -0.07184 & -0.06033 & -0.04362 \\
\hline $\mathrm{F}^{7+}$ & -0.12138 & -0.07815 & -0.06137 & -0.04358 \\
\hline $\mathrm{Ne}^{8+}$ & -0.12801 & -0.08450 & -0.06229 & -0.04362 \\
\hline
\end{tabular}

-0.044 hartree $^{43}$ as expected from the scaling theorem, all three DFT procedures overestimate the correlation energy at high densities, with the extent increasing in the order: PW91(VWN5) < P86(VWN5) < P86(VWN3). The PW91(VWN5) energies grow only slowly as the nuclear charge (and hence the compression) increases, but the P86(VWN3) and P86(VWN5) energies rise much more rapidly, with P86(VWN3) giving larger deviations than P86(VWN5) because of the less accurate description of the UEG by VWN3 when compared with VWN5, as discussed in the previous section. The systematic study by Jarzecki and Davidson drew the same conclusions. ${ }^{44}$ We note that the P86(VWN5) and PW91(VWN5) energies are similar for $\mathrm{H}^{-}, \mathrm{He}, \ldots ., \mathrm{C}^{4+}$, and one might therefore expect that P86(VWN5) and PW91(VWN5) will yield similar total energies for systems with intermediate densities. As we shall see, this is indeed the case.

Table 5 shows the vibrationless total energies for selected atoms and molecules, and the vibrationless atomization energies for these molecules, according to the B-P86(VWN3), B-P86(VWN5), and B-PW91(PW91) procedures. As the nuclear charge increases, the atomic B-P86(VWN5) energies fall slightly more rapidly than the B-PW91(VWN5) energies and the B-P86(VWN3) energies fall even more rapidly. Similar trends are found for the molecular energies as the number of electrons increases. Although the differences between BP86(VWN5) and B-PW91(VWN5) are small (up to 0.02 hartree for $\left.\mathrm{F}_{2}\right)$, the differences between B-P86(VWN3) and BP86(VWN5) are generally very large $(>0.1$ hartree for the four molecules other than $\mathrm{H}_{2}$ ).

These results are consistent with the observations in Table 4, in that the P86 correlation energies at high densities are much lower than the PW91 values, and the effect is magnified when the VWN3 functional is used. The correlation energy overestimation is more dramatic for molecules than for atoms for B-P86, particularly B-P86(VWN3).

We note that the B-P86(VWN3) total energy for a given species in Table 5 is more negative than that for BP86(VWN5) by approximately $50 \mathrm{~kJ} \mathrm{~mol}^{-1}$ per electron, as indicated by the $\Delta(\mathrm{B}-\mathrm{P} 86)=[\mathrm{B}-\mathrm{P} 86(\mathrm{VWN} 3)-\mathrm{B}-\mathrm{P} 86-$ (VWN5) $] / n_{\mathrm{e}}$ values. An examination of the total energies for the species in the E3 set shows that this is generally true
Table 5. Vibrationless Total Energies (hartree) for Selected Atomic and Molecular Species, Vibrationless Total Atomization Energies $\left(\mathrm{kJ} \mathrm{mol}^{-1}\right)$ for the Molecules, and Differences in Total Energies Per Electron [ $\Delta(\mathrm{B}-\mathrm{P} 86), \mathrm{kJ}$ $\left.\mathrm{mol}^{-1}\right]^{a}$

\begin{tabular}{|c|c|c|c|c|}
\hline GGA & B-P86 & B-P86 & B-PW91 & $\Delta(\mathrm{B}-\mathrm{P} 86)^{\circ}$ \\
\hline $\begin{array}{c}\text { LDA } \\
\text { functional }\end{array}$ & VWN3 & VWN5 & VWN5 & \\
\hline \multicolumn{5}{|c|}{ total energy } \\
\hline $\mathrm{H}$ & -0.51777 & -0.49996 & -0.50403 & -46.8 \\
\hline $\mathrm{He}$ & -2.94261 & -2.90520 & -2.90646 & -49.1 \\
\hline $\mathrm{Li}$ & -7.53517 & -7.48066 & -7.48464 & -47.7 \\
\hline $\mathrm{Be}$ & -14.73182 & -14.65847 & -14.65892 & -48.1 \\
\hline B & -24.74401 & -24.65121 & -24.64961 & -48.7 \\
\hline $\mathrm{C}$ & -37.96130 & -37.84906 & -37.84562 & -49.1 \\
\hline $\mathrm{N}$ & -54.72912 & -54.59771 & -54.59271 & -49.3 \\
\hline $\mathrm{O}$ & -75.24253 & -75.08789 & -75.08050 & -50.8 \\
\hline $\mathrm{F}$ & -99.93782 & -99.75969 & -99.75066 & -52.0 \\
\hline $\mathrm{Ne}$ & -129.16205 & -128.96066 & -128.95039 & -52.9 \\
\hline $\mathrm{H}_{2}$ & -1.21329 & -1.17771 & -1.17667 & -46.7 \\
\hline $\mathrm{CH}_{4}$ & -40.72136 & -40.53213 & -40.52501 & -49.7 \\
\hline $\mathrm{N}_{2}$ & -109.84910 & -109.57458 & -109.56255 & -51.5 \\
\hline $\mathrm{O}_{2}$ & -150.71371 & -150.39840 & -150.38115 & -51.7 \\
\hline $\mathrm{F}_{2}$ & -199.95793 & -199.59805 & -199.57711 & -52.5 \\
\hline \multicolumn{5}{|c|}{ atomization energy } \\
\hline $\mathrm{H}_{2}$ & 466.7 & 466.8 & 442.7 & \\
\hline $\mathrm{CH}_{4}$ & 1808.9 & 1793.8 & 1741.4 & \\
\hline $\mathrm{N}_{2}$ & 1026.2 & 995.5 & 990.1 & \\
\hline $\mathrm{O}_{2}$ & 600.3 & 584.5 & 578.0 & \\
\hline $\mathrm{F}_{2}$ & 216.1 & 206.6 & 199.0 & \\
\hline
\end{tabular}

(Supporting Information, Table S1). This is consistent with the more positive (by $\sim 45 \mathrm{~kJ} \mathrm{~mol}^{-1}$ ) deviations for the IEs and EAs for B-P86(VWN3) when compared with those for B-P86(VWN5), and likewise for B-PW91(VWN3) versus B-PW91(VWN5) (Table 3).

Performance of Hybrid-GGA Functionals B3-P86, B3PW91, and B3-LYP. We now turn our attention to the Becke three-parameter hybrid functionals B3-P86, B3-PW91, and B3LYP. The B3-P86 and B3-PW91 functionals have the form ${ }^{15}$

$$
\begin{aligned}
E_{\mathrm{XC}}= & 0.8 E_{\mathrm{X}}^{\mathrm{S}}+0.2 E_{\mathrm{X}}^{\mathrm{HF}}+0.72 \Delta E_{\mathrm{X}}^{\mathrm{B} 88}+E_{\mathrm{C}}^{\mathrm{VWN}} \\
& +0.81 \Delta E_{\mathrm{C}}^{\mathrm{GGA}}
\end{aligned}
$$

while B3-LYP is defined by ${ }^{15}$

$$
\begin{aligned}
E_{\mathrm{XC}}= & 0.8 E_{\mathrm{X}}^{\mathrm{S}}+0.2 E_{\mathrm{X}}^{\mathrm{HF}}+0.72 \Delta E_{\mathrm{X}}^{\mathrm{B} 88}+0.19 E_{\mathrm{C}}^{\mathrm{VWN}} \\
& +0.81 E_{\mathrm{C}}^{\mathrm{LYP}}
\end{aligned}
$$

The MADs and MDs for the E3 set and its subsets for these three procedures, with a variety of underlying LDA correlation functionals, are shown in Tables 6 and 7, respectively. In addition to examining the effect of the underlying LDA functionals on the performance of B3-P86 and B3-PW91, we have also investigated the influence of the supplementary LDA correlation functional in B3-LYP.

In general, the hybrid functionals (Table 6), as expected, perform better than their pure-GGA equivalents (Table 2), but they show similar trends. Thus, the B3-PW91(VWN5) and B3PW91(PW92) procedures yield the lowest MAD values of 17.3 and $17.1 \mathrm{~kJ} \mathrm{~mol}^{-1}$, respectively, for the E3 set. B3-LYP is almost 
Table 6. Mean Absolute Deviations from Benchmark Values ( $\mathrm{kJ} \mathrm{mol}^{-1}$ ) for the B3-P86, B3-PW91, and B3-LYP Procedures with a Variety of Underlying Correlation LDA Functionals for the E3 Set and its Subsets ${ }^{a}$

\begin{tabular}{|c|c|c|c|c|c|c|c|c|c|c|}
\hline \multirow{2}{*}{$\frac{\text { hybrid-GGA }}{\text { LDA functional }}$} & \multicolumn{4}{|c|}{ B3-P86 } & \multicolumn{3}{|c|}{ B3-PW91 } & \multicolumn{3}{|c|}{ B3-LYP } \\
\hline & VWN3 & PZ81 & VWN5 & PW92 & VWN3 & VWN5 & PW92 & VWN3 & VWN5 & PW92 \\
\hline E3 & 54.6 & 38.6 & 32.9 & 32.7 & 55.2 & 17.3 & 17.1 & 19.7 & 22.6 & 22.1 \\
\hline E2 & 66.3 & 44.4 & 35.8 & 35.5 & 66.1 & 14.3 & 14.0 & 16.7 & 20.6 & 20.0 \\
\hline E0 & 29.2 & 24.4 & 19.3 & 19.2 & 30.2 & 12.1 & 12.0 & 12.9 & 13.3 & 13.2 \\
\hline W4/08 & 37.7 & 30.7 & 23.0 & 22.8 & 39.5 & 13.5 & 13.4 & 14.6 & 15.0 & 15.0 \\
\hline $\mathrm{DBH} 24$ & 21.0 & 20.8 & 21.2 & 21.1 & 19.6 & 16.0 & 15.9 & 17.4 & 17.4 & 17.4 \\
\hline HB16 & 4.3 & 3.6 & 3.6 & 3.6 & 5.1 & 2.9 & 2.9 & 2.4 & 2.3 & 2.3 \\
\hline WI9/04 & 1.7 & 1.8 & 1.8 & 1.8 & 1.5 & 2.2 & 2.2 & 1.9 & 2.0 & 1.9 \\
\hline G2/97' & 68.8 & 38.4 & 32.5 & 32.2 & 64.8 & 15.5 & 15.2 & 14.6 & 18.2 & 17.1 \\
\hline $\mathrm{G} 2 / 97^{\prime} \Delta H_{\mathrm{f}}$ & 96.8 & 75.6 & 59.7 & 59.2 & 97.9 & 15.7 & 15.1 & 14.7 & 22.3 & 19.3 \\
\hline IE & 52.4 & 16.5 & 17.4 & 17.2 & 45.7 & 17.9 & 17.8 & 17.0 & 19.5 & 19.5 \\
\hline EA & 57.4 & 16.1 & 15.2 & 15.2 & 48.0 & 13.0 & 12.8 & 12.1 & 11.5 & 11.6 \\
\hline PA & 4.6 & 4.0 & 4.0 & 4.0 & 6.4 & 5.7 & 5.6 & 4.3 & 4.6 & 4.6 \\
\hline E1 & 103.8 & 78.5 & 60.9 & 60.4 & 109.7 & 14.5 & 14.2 & 25.0 & 33.4 & 33.1 \\
\hline $\mathrm{G} 3 / 99^{\prime} \Delta H_{\mathrm{f}}$ & 177.9 & 133.6 & 102.7 & 101.7 & 186.6 & 20.2 & 19.8 & 36.2 & 50.7 & 50.5 \\
\hline $\mathrm{ADD}$ & 7.9 & 5.5 & 5.2 & 5.2 & 12.4 & 4.6 & 4.6 & 13.9 & 15.4 & 14.7 \\
\hline ABS & 9.4 & 9.2 & 8.7 & 8.8 & 9.6 & 8.8 & 8.8 & 8.9 & 9.2 & 8.8 \\
\hline PR8 & 9.8 & 8.9 & 8.7 & 8.6 & 13.0 & 7.6 & 7.7 & 7.6 & 7.8 & 7.9 \\
\hline $\mathrm{DSD}^{\prime}$ & 26.0 & 24.5 & 25.8 & 25.7 & 28.4 & 24.8 & 24.6 & 26.9 & 27.6 & 27.4 \\
\hline $\mathrm{S} 22$ & 11.9 & 12.9 & 13.0 & 13.0 & 10.2 & 16.3 & 16.3 & 14.9 & 15.3 & 15.2 \\
\hline MB08 & 31.0 & 28.8 & 30.4 & 30.2 & 34.6 & 28.4 & 28.1 & 30.3 & 31.2 & 30.9 \\
\hline $\mathrm{Pd}$ & 4.3 & 5.0 & 4.7 & 4.8 & 4.6 & 4.7 & 4.7 & 6.3 & 6.5 & 6.5 \\
\hline Grubbs & 17.5 & 21.1 & 21.4 & 21.6 & 10.6 & 27.5 & 27.5 & 46.7 & 47.8 & 47.6 \\
\hline
\end{tabular}

${ }^{a_{T}}$ The 6-311++G(3df,3pd) basis set was employed for all elements except Pd and Ru, for which the def2-TZVP basis set was used, together with the matching effective core potential.

Table 7. Mean Deviations from Benchmark Values $\left(\mathrm{kJ} \mathrm{mol}^{-1}\right)$ for the B3-P86, B3-PW91, and B3-LYP Procedures with a Variety of Underlying Correlation LDA Functionals for the E3 Set and its Subsets ${ }^{a}$

\begin{tabular}{|c|c|c|c|c|c|c|c|c|c|c|}
\hline \multirow{2}{*}{$\frac{\text { hybrid-GGA }}{\text { LDA functional }}$} & \multicolumn{4}{|c|}{ B3-P86 } & \multicolumn{3}{|c|}{ B3-PW91 } & \multicolumn{3}{|c|}{ B3-LYP } \\
\hline & VWN3 & PZ81 & VWN5 & PW92 & VWN3 & VWN5 & PW92 & VWN3 & VWN5 & PW92 \\
\hline E3 & -14.4 & -17.9 & -14.5 & -14.4 & -15.2 & -3.9 & -3.6 & 1.1 & 1.5 & 1.1 \\
\hline E2 & -21.0 & -24.7 & -19.8 & -19.6 & -24.2 & -3.8 & -3.4 & 7.2 & 8.2 & 7.5 \\
\hline E0 & 20.0 & 14.3 & 6.3 & 6.6 & 21.9 & -3.9 & -3.8 & -4.7 & -7.3 & -7.2 \\
\hline W4/08 & 34.1 & 25.8 & 14.0 & 14.4 & 36.5 & -2.1 & -2.0 & -3.0 & -6.8 & -6.7 \\
\hline $\mathrm{DBH} 24$ & -19.4 & -19.4 & -19.8 & -19.7 & -17.9 & -14.8 & -14.7 & -17.0 & -17.0 & -17.0 \\
\hline HB16 & 3.8 & 2.9 & 2.9 & 2.8 & 4.8 & 0.5 & 0.5 & 1.6 & 1.2 & 1.4 \\
\hline WI9/04 & -1.7 & -1.8 & -1.8 & -1.8 & -1.5 & -2.2 & -2.2 & -1.9 & -2.0 & -1.9 \\
\hline G2/97' & -4.3 & -22.3 & -16.6 & -16.5 & -9.2 & -3.2 & -2.9 & 5.4 & 4.3 & 3.1 \\
\hline $\mathrm{G} 2 / 97^{\prime} \Delta H_{\mathrm{f}}$ & -95.7 & -73.6 & -56.4 & -56.0 & -96.8 & -9.2 & -8.4 & 8.8 & 19.5 & 16.3 \\
\hline IE & 52.2 & 6.0 & 4.8 & 4.6 & 45.4 & -1.9 & -2.0 & 0.0 & -8.9 & -9.0 \\
\hline EA & 57.4 & 14.8 & 13.1 & 13.2 & 48.0 & 3.6 & 3.6 & 9.2 & 0.9 & 0.8 \\
\hline PA & 2.3 & -0.1 & 0.2 & 0.1 & 4.9 & 4.4 & 4.3 & -3.0 & -3.5 & -3.4 \\
\hline E1 & -99.6 & -73.7 & -55.8 & -55.2 & -105.5 & -5.0 & -4.1 & 24.2 & 33.1 & 32.8 \\
\hline $\mathrm{G} 3 / 99^{\prime} \Delta H_{\mathrm{f}}$ & -177.9 & -133.0 & -100.9 & -100.0 & -186.6 & -11.8 & -10.2 & 35.4 & 50.7 & 50.4 \\
\hline $\mathrm{ADD}$ & -6.8 & -3.1 & -2.8 & -2.7 & -12.3 & 0.8 & 0.9 & 13.9 & 15.4 & 14.7 \\
\hline $\mathrm{ABS}$ & 9.4 & 9.2 & 8.7 & 8.8 & 9.6 & 8.8 & 8.8 & 8.9 & 9.2 & 8.8 \\
\hline PR8 & -9.8 & -8.9 & -8.7 & -8.6 & -12.7 & -6.6 & -6.6 & 3.2 & 3.6 & 3.5 \\
\hline $\mathrm{DSD}^{\prime}$ & 1.9 & -1.2 & -1.5 & -1.9 & 6.8 & -4.1 & -4.1 & -13.8 & -14.8 & -14.6 \\
\hline S22 & 11.9 & 12.9 & 13.0 & 13.0 & 10.2 & 16.3 & 16.3 & 14.9 & 15.3 & 15.2 \\
\hline MB08 & 0.3 & -4.0 & -4.4 & -4.8 & 7.3 & -8.4 & -8.3 & -21.9 & -23.3 & -23.0 \\
\hline $\mathrm{Pd}$ & -1.7 & -2.3 & -2.1 & -2.2 & -1.4 & -3.0 & -3.0 & -0.7 & -0.8 & -0.8 \\
\hline Grubbs & 17.5 & 21.1 & 21.4 & 21.6 & 9.4 & 27.5 & 27.5 & 46.7 & 47.8 & 47.6 \\
\hline
\end{tabular}

${ }^{a_{T}}$ The 6-311++G(3df,3pd) basis set was employed for all elements except Pd and Ru, for which the def2-TZVP basis set was used, together with the matching effective core potential.

as good, with MADs of $\sim 20-22 \mathrm{~kJ} \mathrm{~mol}^{-1}$. This is followed by B3-P86, with MADs spanning a range from 32.7 to $54.6 \mathrm{~kJ}$ $\mathrm{mol}^{-1}$. The worst-performing functional is B3-PW91(VWN3)
$\left(\mathrm{MAD}=55.2 \mathrm{~kJ} \mathrm{~mol}^{-1}\right)$, presumably because of the poor performance of B-PW91(VWN3) (Table 2). 
Like the results for the pure-GGAs, the differences in performance for the hybrid-GGAs on the E3 set are mainly associated with large variations in the MADs for $\Delta H_{\mathrm{f}}$ values and, to a smaller extent, IEs and EAs. For B3-P86, we see that the MADs for atomization energies and $\Delta H_{\mathrm{f}} \mathrm{s}$ (Table 6) decrease with the underlying LDA in the same order as for BP86 (Table 2), i.e., VWN3 > PZ81 > VWN5 PW92. Notably, for the G3/99' $\Delta H_{\mathrm{f}}$ set, the MADs for the various forms of B3P86 are 177.9 (VWN3), 133.6 (PZ81), 102.7 (VWN5), and 101.7 (PW92) kJ mol ${ }^{-1}$. Likewise, B3-PW91(VWN3) has much larger MADs for $\Delta H_{\mathrm{f}} \mathrm{s}$ than those for B3-PW91(VWN5) and B3-PW91(PW92). For IEs and EAs, B3-P86(VWN3) and B3-PW91(VWN3) have disproportionately large MADs ( 45$\left.60 \mathrm{~kJ} \mathrm{~mol}^{-1}\right)$ when compared with the other procedures $(\sim 10-$ $20 \mathrm{~kJ} \mathrm{~mol}^{-1}$ ), and this is again in accord with the characteristics of their pure-GGA counterparts (Table 2).

Examination of the MD values in Table 7 shows that the large deviations in $\Delta H_{\mathrm{f}}$ s for B3-P86(VWN3) and for B3PW91(VWN3) can be attributed to systematic overstabilization of molecules relative to atoms. In addition, the IE and EA values are consistently overestimated in these cases when compared with other procedures. These variations in the MD values are also consistent with the corresponding results for the pure functionals (Table 3 ). An important message that emerges from the results in Tables 6 and 7 is that both B3-P86 and B3PW91 benefit from the VWN5 or PW92 functionals, compared with VWN3.

We now turn our attention to B3-LYP. In general, regardless of the choice of the supplementary correlation LDA, B3-LYP gives MADs for the subsets of $\mathrm{E} 3$ that are comparable to those for the best performing functional examined in the present study, namely B3-PW91(PW92) (Table 6). Notable exceptions are the G3/99' $\Delta H_{\mathrm{f}}$ and the Grubbs sets, for which the MADs for B3-LYP are larger than those for B3-PW91(PW92) by more than $20 \mathrm{~kJ} \mathrm{~mol}^{-1}$. We observe that B3-LYP(VWN3) has a somewhat lower overall MAD for the E3 set than B3LYP(VWN5) and B3-LYP(PW92). This is consistent with the findings of Hertwig and Koch. ${ }^{45}$

On the Better Performance of B3-LYP(VWN3) than B3LYP(VWN5). The fact that B3-LYP favors the VWN3 functional contrasts starkly with the behavior of B3-P86 and B3-PW91 and is puzzling when one considers that VWN5 is generally believed to offer a more accurate model of electron correlation in the UEG. However, the result can be rationalized by noting that the P86 and PW91 functionals were constructed as gradient corrections to the LDA and their performance should therefore be expected to improve with the accuracy in the underlying approximation to the UEG. On the other hand, the LYP functional was developed from the Colle-Salvetti ${ }^{46}$ correlation wave function and does not make reference to an underlying LDA. Thus, the best LDA functional might not be the most compatible partner for the LYP functional in B3-LYP and, in fact, it is not.

What characteristics of VWN3 make it a better component within B3-LYP than VWN5? To address this question, we reexamine the results for the pure-GGAs. It can be seen from Table 3 that B-LYP behaves differently for $\Delta H_{\mathrm{f}}$ s when compared with B-P86 and B-PW91, with the former showing a systematic overestimation of the $\Delta H_{\mathrm{f}}$ values, while the latter two consistently underestimate $\Delta H_{\mathrm{f}}$. As evident from the comparison of VWN3 and VWN5 for B-P86 and B-PW91 for the evaluation of $\Delta H_{f}, \mathrm{VWN} 3$ leads to greater underestimations of $\Delta H_{\mathrm{f}}$. Presumably, the underestimation of $\Delta H_{\mathrm{f}}$ by VWN3, when scaled down (to 19\%, eq 2) in the formulation of B3LYP, complements the overestimation by LYP. Through this fortuitous cancellation of errors, B3-LYP(VWN3) ends up performing better than B3-LYP(VWN5).

Practical Implications and Recommendations. We note again that B-P86, by construction, employs the PZ81 functional that is also the default setting in Gaussian, and it may benefit from a switch to the more accurate VWN5 or PW92 representation. In addition, we note that the default forms of the B3-type hybrid functionals (as implemented in Gaussian) are B3-P86(VWN3), B3-PW91(PW92), and B3-LYP(VWN3). For B3-P86, we suggest that the use of the VWN5 or PW92 forms of LDA is likely to be advantageous compared with the default VWN3 functional. In the present study, we find that the performance of the default procedures improves in the order B3-P86 < B3-LYP B3-PW91, which is consistent with the general expectations for these functionals. ${ }^{9 b, c}$ In general, we recommend the use of the PW91 gradient correction over P86, due to its demonstrated better performance, as well as its superior behavior in the high-density regime.

\section{CONCLUDING REMARKS}

We have re-examined and analyzed the performance of several popular GGA procedures (B-P86, B-PW91, and B-LYP) and their three-parameter hybrid variants (B3-P86, B3-PW91, and B3-LYP) for the extensive E3 set of thermochemical properties. In particular, we have investigated the dependence of their performance on the underlying correlation LDA functional and gradient correction. The following important points emerge from the present study:

(1) For B-P86 and B3-P86, the overall performance improves with the underlying correlation LDA in the order: VWN3 < PZ81 < VWN5 PW92, which is consistent with the accuracy with which these functionals model the uniform electron gas. As with B-P86 and B3P86, the use of VWN3 for B-PW91 and B3-PW91 leads to large overall errors for the E3 set, and exceedingly large errors in some individual cases, e.g., $-455.6 \mathrm{~kJ}$ $\mathrm{mol}^{-1}$ for the B-PW91(VWN3) $\Delta H_{\mathrm{f}}$ for azulene.

(2) The variation in the overall performance of the various DFT procedures stems largely from variations in their MADs for $\Delta H_{\mathrm{f}} \mathrm{s}$ and, to a smaller extent, for IEs and EAs. For B-P86, B-PW91, B3-P86, and B3-PW91, the use of VWN3 leads to a large overstabilization for molecules relative to atoms. This leads to a large underestimation of $\Delta H_{\mathrm{f}} \mathrm{s}$, especially for the larger molecules in the test set.

(3) When an accurate LDA such as VWN5 or PW92 is employed, the use of the PW91 functional in place of P86 generally yields substantially better agreement with experiment for $\Delta H_{\mathrm{f}}$ s. We ascribe this to the fact that, whereas PW91 almost satisfies the Levy scaling theorem, P86 grossly violates it. This argument is supported by an analysis of the correlation energies for helium-like ions, which demonstrates the serious errors of P86 at high density.

(4) Our results confirm that B3-LYP(VWN3) is more accurate than B3-LYP(VWN5). As before, this is due largely to superior $\Delta H_{\mathrm{f}}$ estimates from the B3-LYP(VWN3) variant which, in turn, result from cancellation between the understabilization of molecules relative to their atoms by B-LYP and a compensating overstabilization by VWN3. 
(5) By default, B-P86 and B3-P86 (in Gaussian) employ the PZ81 and VWN3 functionals, respectively. It may be preferable in these cases to use the more accurate VWN5 or PW92 functionals, but in general, we recommend the use of the PW91 form of GGA over the less sophisticated P86 functional.

\section{ASSOCIATED CONTENT}

\section{(S Supporting Information}

Calculated BMK/6-31+G(2df,p) zero-point vibrational energies (ZPVE), enthalpy corrections at $298 \mathrm{~K}\left(\Delta H_{298}\right)$, electronic energies for the various DFT methods, and comparison of BP86(VWN3) and B-P86(VWN5) electronic energies on a perelectron basis (Table S1) and deviations from benchmark values for the E3 set for these functionals (Table S2). This material is available free of charge via the Internet at http:// pubs.acs.org.

\section{AUTHOR INFORMATION}

\section{Corresponding Author}

*E-mail: chan_b@chem.usyd.edu.au (B.C.); peter.gill@anu. edu.au (P.M.W.G.); radom@chem.usyd.edu.au (L.R.).

Notes

The authors declare no competing financial interest.

\section{ACKNOWLEDGMENTS}

We gratefully acknowledge funding (to L.R.) from the Australian Research Council (ARC) and generous grants of computer time (to L.R.) from the National Computational Infrastructure (NCI) National Facility and Intersect Australia Ltd.

\section{REFERENCES}

(1) For general overviews of density functional theory and its applications, see for example: (a) Parr, R. G.; Yang, W. DensityFunctional Theory of Atoms and Molecules; Oxford University Press: New York, 1989. (b) Koch, W.; Holthausen, M. C. A Chemist's Guide to Density Functional Theory, 2nd ed.; Wiley: New York, 2001. (c) Scuseria, G. E.; Staroverov, V. N. In Theory and Applications of Computational Chemistry: The First Forty Years; Dykstra, C. E., Frenking, G., Kim, K. S., Scuseria, G. E., Eds.; Elsevier, B. V.: Amsterdam, 2005. (d) Sholl, D.; Steckel, J. A. Density Functional Theory: A Practical Introduction; Wiley: Hoboken, 2009.

(2) Slater, J. C. Quantum Theory of Atomic Structure; McGraw-Hill: New York, 1960; Vol. 2, p 14.

(3) Vosko, S. H.; Wilk, L.; Nusair, M. Can. J. Phys. 1980, 58, 1200.

(4) Perdew, J. P.; A. Zunger, A. Phys. Rev. B 1981, 23, 5048.

(5) Perdew, J. P.; Wang, Y. Phys. Rev. B 1992, 45, 13244.

(6) Becke, A. D. Phys. Rev. A 1988, 38, 3098.

(7) Perdew, J. P. Phys. Rev. B 1986, 33, 8822.

(8) Frisch, M. J.; Trucks, G. W.; Schlegel, H. B.; Scuseria, G. E.; Robb, M. A.; Cheeseman, J. R.; Scalmani, G.; Barone, V.; Mennucci, B.; Petersson, G. A.; Nakatsuji, H.; Caricato, M.; Li, X.; Hratchian, H. P.; Izmaylov, A. F.; Bloino, J.; Zheng, G.; Sonnenberg, J. L.; Hada, M.; Ehara, M.; Toyota, K.; Fukuda, R.; Hasegawa, J.; Ishida, M.; Nakajima, T.; Honda, Y.; Kitao, O.; Nakai, H.; Vreven, T.; Montgomery, Jr., J. A.; Peralta, J. E.; Ogliaro, F.; Bearpark, M.; Heyd, J. J.; Brothers, E.; Kudin, K. N.; Staroverov, V. N.; Kobayashi, R.; Normand, J.; Raghavachari, K.; Rendell, A.; Burant, J. C.; Iyengar, S. S.; Tomasi, J.; Cossi, M.; Rega, N.; Millam, N. J.; Klene, M.; Knox, J. E.; Cross, J. B.; Bakken, V.; Adamo, C.; Jaramillo, J.; Gomperts, R.; Stratmann, R. E.; Yazyev, O.; Austin, A. J.; Cammi, R.; Pomelli, C.; Ochterski, J. W.; Martin, R. L.; Morokuma, K.; Zakrzewski, V. G.; Voth, G. A.; Salvador, P.; Dannenberg, J. J.; Dapprich, S.; Daniels, A. D.; Farkas, Ö.;
Foresman, J. B.; Ortiz, J. V.; Cioslowski, J.; Fox, D. J. Gaussian 09, revision A.02; Gaussian, Inc.: Wallingford CT, 2009.

(9) See for example: (a) Goerigk, L.; Grimme, S. Phys. Chem. Chem. Phys. 2011, 13, 6670. (b) Staroverov, V. N.; Scuseria, G. E.; Tao, J.; Perdew, J. P. J. Chem. Phys. 2003, 119, 12129. (c) Reference 1b, pp 137-176 and references therein.

(10) As an "extreme" example, the deviation for the heat of formation for azulene is $-117.2 \mathrm{~kJ} \mathrm{~mol}^{-1}$ for B3-PW91 while for B-P86 it is $-304.2 \mathrm{~kJ} \mathrm{~mol}^{-1}$. . $^{-2}$

(11) Perdew, J. P. In Electronic Structure of Solids '91; Ziesche, P., Eschrig, H., Eds.; Akademie Verlag: Berlin, 1991; p 11.

(12) Lee, C.; Yang, W.; Parr, R. G. Phys. Rev. B 1988, 37, 785.

(13) Becke, A. D. J. Chem. Phys. 1993, 98, 5648.

(14) Johnson, B. G.; Gill, P. M. W.; Pople, J. A. J. Chem. Phys. 1993, 98, 5612 .

(15) Stephens, P. J.; Devlin, F. J.; Chabalowski, C. F.; Frisch, M. J. J. Phys. Chem. 1994, 98, 11623.

(16) Neese, F. WIREs Comput. Mol. Sci. 2012, 2, 73.

(17) Boese, A. D.; Martin, J. M. L. J. Chem. Phys. 2004, 121, 3405.

(18) Chan, B.; Deng, J.; Radom, L. J. Chem. Theory Comput. 2011, 7, 112.

(19) Merrick, J. P.; Moran, D.; Radom, L. J. Phys. Chem. A 2007, 111, 11683.

(20) Obtained from the EMSL Basis Set Exchange: (a) Feller, D. J. Comput. Chem. 1996, 17, 1571. (b) Schuchardt, K. L.; Didier, B. T.; Elsethagen, T.; Sun, L.; Gurumoorthi, V.; Chase, J.; Li, J.; Windus, T. L. J. Chem. Inf. Model. 2007, 47, 1045. (c) https://bse.pnl.gov/bse/ portal (accessed March 2010).

(21) The B3-P86, B3-LYP, and B3-PW91 procedures employ the same values for the three parameters, see ref 15 .

(22) Chan, B.; Radom, L. J. Chem. Theory. Comput. 2011, 7, 2852.

(23) Karton, A.; Tarnopolsky, A.; Lamère, J.-F.; Schatz, G. C.; Martin, J. M. L. J. Phys. Chem. A 2008, 112, 12868.

(24) (a) Zheng, J.; Zhao, Y.; Truhlar, D. G. J. Chem. Theory Comput. 2007, 3, 569. (b) Zheng, J.; Zhao, Y.; Truhlar, D. G. J. Chem. Theory Comput. 2009, 5, 808.

(25) Boese, A. D.; Martin, J. M. L.; Klopper, W. J. Phys. Chem. A 2007, 111, 11122.

(26) Zhao, Y.; Truhlar, D. G. J. Chem. Theory Comput. 2005, 1, 415.

(27) Curtiss, L. A.; Redfern, P. C.; Raghavachari, K.; Pople, J. A. J. Chem. Phys. 1998, 109, 42.

(28) Curtiss, L.; Raghavachari, K.; Redfern, P. C.; Pople, J. A. J. Chem. Phys. 2000, 112, 7374

(29) Lin, C. Y.; Hodgson, J. L.; Namazian, M.; Coote, M. L. J. Phys. Chem. A 2009, 113, 3690.

(30) (a) Guner, V.; Khuong, K. S.; Leach, A. G.; Lee, P. S.; Bartberger, M. D.; Houk, K. N. J. Phys. Chem. A 2003, 107, 11445. (b) Ess, D. H.; Houk, K. N. J. Phys. Chem. A 2005, 109, 9542.

(31) (a) Jurecka, P.; Sponer, J.; Cerny, J.; Hobza, P. Phys. Chem. Chem. Phys. 2006, 8, 1985. (b) Takatani, T.; Hohenstein, E. G.; Malagoli, M.; Marshall, M. S.; Sherrill, C. D. J. Chem. Phys. 2010, 132, 144104.

(32) Schwabe, T.; Grimme, S. J. Phys. Chem. A 2009, 113, 3005.

(33) Quintal, M. M.; Karton, A.; Iron, M. A.; Boese, A. D.; Martin, J. M. L. J. Phys. Chem. A 2006, 110, 709.

(34) Zhao, Y.; Truhlar, D. G. J. Chem. Theory Comput. 2009, 5, 324

(35) Ceperley, D. M.; Alder, B. J. Phys. Rev. Lett. 1980, 45, 566.

(36) Von Barth, U.; Hedin, L. J. Phys. C: Solid State Phys. 1972, 5, 1629.

(37) (a) Levy, M. Int. J. Quantum Chem. 1989, S23, 617. (b) Levy, M. Phys. Rev. A 1991, 43, 4637.

(38) (a) Perdew, J. P. Physica B 1991, 172, 1. (b) Levy, M.; Perdew, J. P. Phys. Rev. B 1993, 48, 11638. (c) Levy, M.; Perdew, J. P. Int. J. Quantum Chem. 1994, 49, 539.

(39) An alternative form of the PW91 gradient correction has been proposed that rigorously satisfies the high-density condition, see ref $38 \mathrm{~b}$. However, the original form of ref 11 is implemented in many widely used computational chemistry software packages. 
(40) (a) Pitzer, R. M. J. Chem. Phys. 1967, 46, 4871. (b) Hehre, W. J.; Stewart, R. F.; Pople, J. A. J. Chem. Phys. 1969, 51, 2657.

(41) Exceptions to this general rule occur for highly electronegative atoms such as $\mathrm{F}$ and $\mathrm{O}$.

(42) The cc-pCVQZ basis set ${ }^{20}$ is employed in the calculation of the DFT and CCSD correlation energies for a consistent treatment of the 1s electrons for all species. Correlation energies for CCSD were obtained with converged Hartree-Fock reference wave functions, while DFT correlation energies were evaluated self-consistently together with the B88 exchange functional.

(43) Loos, P.-F.; Gill, P. M. W. Chem. Phys. Lett. 2010, 500, 1.

(44) Jarzecki, A. J.; Davidson, E. R. Phys Rev. A 1998, 58, 1902.

(45) Hertwig, R. H.; Koch, W. Chem. Phys. Lett. 1997, 268, 345.

(46) Colle, R.; Salvetti, O. Theor. Chim. Acta 1975, 37, 329. 